\title{
DIFFERENCES IN CORNEO-SCLERAL TOPOGRAPHIC PROFILE BETWEEN HEALTHY AND KERATOCONUS CORNEAS
}

\author{
David P Piñero, $\mathrm{PhD}^{1,2}$ \\ Antonio Martínez-Abad, $\mathrm{MSc}^{1}$ \\ Roberto Soto-Negro, OD MSc ${ }^{2}$ \\ Pedro Ruiz-Fortes, OD, MSc ${ }^{2}$ \\ Rafael J Pérez-Cambrodí, OD PhD² \\ Miguel Angel Ariza-Gracia, $\mathrm{PhD}^{3}$ \\ Gonzalo Carracedo, $\mathrm{PhD}^{4}$
}

From:

${ }^{1}$ Group of Optics and Visual Perception. Department of Optics, Pharmacology and Anatomy, University of Alicante, Spain

${ }^{2}$ Department of Ophthalmology (OFTALMAR), Vithas Medimar International Hospital, Alicante, Spain

${ }^{3}$ Institute of Engineering of Aragón (I3A), University of Zaragoza, Zaragoza, Spain ${ }^{4}$ Complutense University of Madrid, Madrid, Spain

\section{Corresponding author:}

David P. Piñero

Department of Optics, Pharmacology and Anatomy.University of Alicante.

Crta San Vicente delRaspeig s/n 03016

San Vicente delRaspeig, Alicante, Spain

Tel: +34-965903500, Fax: +34-965903464 
e-mail: david.pinyero@ua.es

\section{Disclosure}

The authors have no proprietary or commercial interest in the medical devices that are involved in this manuscript. 


\begin{abstract}
Purpose: To evaluate the differences in corneo-scleral topographic profile between healthy and keratoconus eyes, and their potential diagnostic ability for keratoconus detection.

Methods: Prospective comparative study including 21 keratoconic eyes (11 patients) and 88 healthy eyes ( 88 patients). In all cases, a complete eye exam was performed including an evaluation of the corneo-scleral profile. The diagnostic ability of corneoscleral topographic parameters to detect keratoconus was evaluated using the receiver operating characteristic (ROC) curve.
\end{abstract}

Results: A significant lower inferior tangent angle at limbus (ITA) was found in the keratoconic group compared to the control group $(\mathrm{p}=0.024)$. Regarding sagittal heights, significant differences between groups were found in temporal sagittal height (TSH) for $11 \mathrm{~mm}(\mathrm{p}=0.040), 12 \mathrm{~mm}(\mathrm{p}=0.041)$ and $13 \mathrm{~mm}$ corneal chords $(\mathrm{p}=0.040)$, difference between temporal and nasal sagittal heights (T-NSH) for $12 \mathrm{~mm}(\mathrm{p}=0.025)$ and $13 \mathrm{~mm}$ $(\mathrm{p}=0.034)$, and maximum sagittal height $(\mathrm{MaxSH})$ for $12 \mathrm{~mm}(\mathrm{p}=0.043)$, with higher values in keratoconus. In bilateral cases, these differences were not found when comparing with the least severe keratoconus eye. Statistical significance for the ROC curve was only found for ITA $(p=0.025), 12-\mathrm{mm}(p=0.048)$ and 13-mm TSH $(p=0.042)$, and 13-mm T-NSH $(p=0.037)$, with cutoff values associated to limited values of sensitivity and specificity.

Conclusions: The corneo-scleral profile in keratoconus presents higher levels of asymmetry compared to healthy eyes, especially in eyes with moderate and advanced stages of the disease. The diagnostic accuracy of corneo-scleral topographic data alone 
for keratoconus detection is limited and must be used in conjunction with other clinical parameters.

Keywords: keratoconus, corneo-scleral topography, profilometry, sagittal height 


\section{Introduction}

Keratoconus is a corneal disease characterised by stromal thinning and conical protrusion that leads progressively to increasing levels of corneal irregularity and visual degradation. ${ }^{1}$ These changes ensue from the alteration of the characteristics of the collagen lamellae that weaken the corneal structure. ${ }^{2-4}$ Specifically, the highly regular arrangement of the stromal superimposed lamellae is lost and results in a weakened tensile strength to the cornea. ${ }^{2}$ Furthermore, microfibril bundles are concentrated below the epithelium whereas they are absent between the anterior stroma and the Descemet's membrane, which is the opposite distribution than that found in normal corneas. ${ }^{2}$ These structural alterations lead to corneal deformation and the generation of an irregular corneal profile. ${ }^{1}$

Several studies have already reported the common alterations of the geometric profile of the cornea that occur in keratoconus, ${ }^{1}$ such as the presence of superior-inferior asymmetry, ${ }^{5}$ local steepening of the cornea, ${ }^{6}$ abnormal elevation, ${ }^{7}$ increment in higher order aberrations (HOAs), ${ }^{8}$ increase in the level of irregularity, ${ }^{5}$ increased trend to prolateness, ${ }^{8}$ and induction of significant amount of astigmatism. ${ }^{5,9}$ Although there is evidence of the presence of deep changes in the sclera and its homogenization in corneal ectasia, ${ }^{10,11}$ there are no studies reporting whether significant alterations in the scleral geometric profile occur in keratoconus. One of the potential reasons for this fact is the lack of a reliable device for the characterization of the geometric corneo-scleral profile in clinical setting. Now, thanks to the latest technical advances in imaging, there is diagnostic technology with the ability of providing a non-invasive analysis of the corneo-scleral topography. ${ }^{12,13}$ In this vein, the aim of the current study is to evaluate and characterise the differences in corneo-scleral topographic profiles between healthy 
eyes and eyes with keratoconus, as well as at evaluating the potential diagnostic ability for the detection of keratoconus of new sclera-corneal topographic indices available thanks to this device.

\section{Material and methods}

\section{Patients}

The prospective, non-randomized and comparative study comprised 21 keratoconic eyes of 11 patients, and a control group with 88 eyes from 88 patients. Only one eye was randomly selected in each patient from the control group to avoid the undesired statistical correlation that often exists between the two eyes of the same individual. In the keratoconus group, a total of 10 patients with bilateral keratoconus were included but all of them had asymmetric keratoconus. In other words, the two eyes of the same patient showed different keratoconus grades according to the AmslerKrumeich grading system. ${ }^{8}$ Specifically, the following combinations in fellow eyes of the same patient were observed: grade I-III (3 patients), grade II-III (1 patient), grade IIV (3 patients), grade I-II ( 2 patients), and grade III-IV (1 patient). In all bilateral keratoconus cases, the left eye showed a less severe stage of the disease. In both groups, measurements were performed with the same clinical protocol and with the same corneo-scleral topographic device which was available at the Optometric Clinic of the University of Alicante and the Department of Ophthalmology (OFTALMAR) of the Vithas Medimar International Hospital (Alicante, Spain). This study was approved by the ethics committee of the University of Alicante and was performed in accordance with the ethical standards laid down in the 1964 Declaration of Helsinki. Written 
informed consent was obtained from all subjects, being free to withdraw participation at any time without reason.

The inclusion criterion for the control group was healthy eyes with absence of any previous ocular surgery. The inclusion criterion for the keratoconus group was the diagnosis of keratoconus according to the standard criteria: the presence of an asymmetric bowtie pattern in corneal topography and at least one keratoconus clinical sign on slit-lamp, such as stromal thinning, conical protrusion of the cornea at the apex, Fleischer ring, Vogt striae or anterior stromal scar. ${ }^{1}$ Exclusion criteria in both control and keratoconus groups were previous ocular surgery and any other active ocular disease. Patients wearing contact lenses were asked to discontinue them use before our examination for a period of 2 weeks for soft contact lenses and for a period of 1 month for rigid gas permeable contact lenses.

\section{Examination protocol}

All patients underwent a complete eye examination including the following tests: anamnesis, measurement of uncorrected (UDVA) and best corrected distance visual acuity (BCDVA), manifest refraction, slit-lamp biomicroscopy, and corneoscleral topographic evaluation with the Eye Surface Profiler (ESP) from Eaglet Eye b.v. (Houten, The Netherlands). This topographer is based on the principle of Fourier domain profilometry and consists of two blue-light fringe projectors and a centrally positioned camera equipped with a yellow filter. ${ }^{14}$ In particular, an area of up to $20 \mathrm{~mm}$ in diameter can be evaluated with more than 250,000 points, covering the entire cornea, limbus and a large part of the sclera (conjunctiva) to image the corneo-scleral

topography (Figure 1). ${ }^{14}$ The accuracy of the system in the determination of the elevation of the corneal surface is comparable to those achievable with keratoscopy- 
based instruments, such as Placido disk videokeratoscopy, but including a wider region of the anterior eye surface. ${ }^{14}$ The actual determination of the eye height is carried out by a best-fit bi-sphere model (Figure 2).

To acquire the measurements, subjects were asked to put their chin on the headrest of the device and to focus on the internal instrument's target. Afterwards, the examiner aligned the instrument until obtaining a sufficiently good image quality. For the scleral data acquisition with the ESP system, a fluorescein dye was instilled once the initial setup was achieved. In particular, a homogeneous dye was obtained after moistening fluorescein sodium ophthalmic strips (BioGlo strips, $1 \mathrm{mg}$ fluorescein sodium, HUB Pharmaceuticals LLC, Rancho Cucamonga, CA, USA) with an eye lubricant (Systane, Alcon, Fort Worth, Texas, USA) according to the recommendations of the manufacturer. In the present study, the following parameters were evaluated and recorded with this corneo-scleral topography system (Figure 3): flattest simulated keratometric reading $(\mathrm{SimKf})$, steepest simulated keratometric reading (SimKs), keratometric astigmatism (Ast), corneal eccentricity (e), inner best fit sphere (BFSi) calculated as the best fit sphere obtained by least squares method considering all corneal points from the center to the limbus, limbus best fit sphere (BFSl) calculated as the best fit sphere obtained by least squares method considering all points conforming the limbus following the algorithm described for its detection, ${ }^{15,16}$ outer best fit sphere (BFSo) calculated as the best fit sphere obtained by least squares method considering all points from the conjunctival surface detected, mean corneal radius (rc), mean scleral radius (rs), horizontal visible iris diameter (HVID), mean sagittal height (distance from corneal apex to the line defined by the chord selected) for a chord of $11,12,13$ and 14 mm (MSH11, MSH12, MSH13, and MSH14), temporal (TSH11, TSH12, TSH13, and TSH14) and nasal sagittal heights (NSH11, NSH12, NSH13, and NSH14) for the same 
chords, difference between temporal and nasal sagittal heights for the same chords (TNSH11, T-NSH12, T-NSH13, and T-NSH14), maximum (MaxSH11, MaxSH12, MaxSH13, and MaxSH14) and minimum sagittal height (MinSH11, MinSH12, MinSH13, and MinSH14) for the same chords, and nasal (NTA), temporal (TTA), superior (STA) and inferior tangent angles (ITA) at limbus (angle defined by the line tangent to the limbus and the ocular surface).

\section{Statistical analysis}

The statistical analysis was carried out with the SPSS statistics software package version 15.0 (IBM, Armonk, EEUU). The Kolmogorov-Smirnov test was used to determine the normality of all data. Different statistical tests were used to analyze differences between groups: the unpaired t-Student test was used when variables were normally distributed, whereas the U Mann-Whitney test was used when variables were not normally distributed. Differences were considered to be statistically significant when the associated p-value was lower than a 5\% (p-value $<0.05)$. Finally, Pearson and Spearman correlation coefficients, which do and do not assume normality respectively, were calculated to assess in the relationship between different variables.

The diagnostic ability of the different corneo-scleral parameters to detect keratoconus was evaluated using the receiver operating characteristic (ROC) curve analysis, which shows the relationship between sensitivity and 1-specificity. Sensitivity is considered as the number of pathological cases that are correctly detected, and specificity is considered as the number of non-pathological cases that have a negative test result. This analysis also provides with the area under the ROC curve and its corresponding statistical significance, which enables the clinician to determine the diagnostic accuracy of any clinical parameter evaluated. Likewise, the optimal cutoff 
point is defined such that presents the best trade-off between high sensitivity and high specificity.

\section{Results}

\section{Comparative analysis}

The sample included a total of 88 control eyes $(80.7 \%)$ of 88 patients and 21 keratoconus eyes $(19.3 \%)$ of 21 patients. The mean age of patients was 38.4 years (SD: 12.9, median: 38.0, range: 21 to 73 years). Table 1 summarizes the demographic, visual, and refractive data of the two groups evaluated. A significantly higher cylinder and a worse CDVA was found when comparing the keratoconus and the control groups $(\mathrm{p}<0.001)$.

Table 2 summarizes the corneal topographic outcomes obtained in both the keratoconus and the control groups. Significantly higher values of keratometric readings, eccentricity and corneal astigmatism were found when comparing the keratoconus and the control groups $(\mathrm{p}<0.001)$. The difference in BFSi between groups was in the limit of statistical significance $(\mathrm{p}=0.053)$, with a trend to lower values in the keratoconus group. Likewise, a significantly lower ITA was found in the keratoconus group compared to the control group $(\mathrm{p}=0.024)$. Regarding the sagittal heights (see in

table 3), significant differences between groups were found in TSH11 ( $\mathrm{p}=0.040)$, TSH12 $(p=0.041)$, TSH13 $(p=0.040)$, T-NSH12 $(p=0.025)$, T-NSH13 $(p=0.034)$, and MaxSH12 $(p=0.043)$, with higher values in the keratoconus group. When the comparison was made with only right and left eyes of the keratoconus groups, the same trends were observed, although some differences did not reach statistical significance when the left eye (the least severe keratoconus eye in each bilateral case) of the 
keratoconus group were used for the analysis (SimKf, e, BFSo, $r_{c}$, TTA, and different sagittal height parameters).

\section{Correlation between corneal and scleral parameters}

Table 4 summarizes some of the significant correlations between corneal and scleral data found in both groups. In the control group, correlations for the scleral geometric data and the sagittal heights with different corneal parameters were found, but being most of them weak. Only strongly significant and inverse correlations of rc with TSH12 $(\mathrm{r}=-0.808, \mathrm{p}<0.0001)$ and MaxSH12 $(\mathrm{r}=-0.843, \mathrm{p}<0.0001)$ were found. Likewise, good correlations of MaxSH12 with keratometric readings (SimKs: $r=0.701$, $\mathrm{p}<0.0001$; SimKf: $r=0.760, \mathrm{p}<0.0001)$ and BFSi $(r=-0.783, \mathrm{p}<0.0001)$ were observed. In the keratoconus group, few correlations between the corneal and the scleral data were found, being statistically significant: BFS0-BFSi $(r=0.567, p=0.007)$ (see in figure 4), BFS0-BFS1 $(r=0.726, p<0.0001)$ (see in figure 5), TSH12-rc $(r=-0.777, p<0.0001)$, TSH12-SimKf $(r=0.545, p=0.016)$, MaxSH12-rc $(r=-0.773, p<0.0001)$, MaxSH12-BFSi $(\mathrm{r}=-0.748, \quad \mathrm{p}<0.0001), \quad$ MaxSH12-SimKs $\quad(\mathrm{r}=0.716, \quad \mathrm{p}<0.0001), \quad$ MaxSH12-SimKf $(\mathrm{r}=0.739, \mathrm{p}<0.0001)$, and MaxSH12-Ast $(\mathrm{r}=-0.434, \mathrm{p}=0.049)$.

\section{ROC curve analysis}

The ROC curve analysis for the detection of keratoconus was performed using only those parameters that presented significant differences between groups: ITA, TSH11, TSH12, TSH13, T-NSH12, T-NSH13, and MaxSH12 (see in figure 4 and table 5). Statistical significance for the ROC curve was only found for ITA ( $p=0.025)$, TSH12 $(p=0.048)$, TSH13 $(p=0.042)$, and T-NSH13 $(p=0.037)$, with cutoff values associated to limited values of sensitivity and specificity (Figure 6). 


\section{Discussion}

In the present study, we aim at confirming if the sclera-conjunctival profile is altered by the keratoconus disease. To do so, we compared the healthy and the keratoconus corneo-scleral profile using a Fourier domain profilometer. This profilometer has previously been validated ${ }^{12,14}$ and used for different clinical purposes such as the measurement of the scleral radius, ${ }^{12}$ the measurement of the limbus shape, ${ }^{15,16}$ or the evaluation of the scleral changes with accommodation. ${ }^{17}$ Using calibrated artificial surfaces, the ESP system showed a root-mean-square accuracy below $10 \mu \mathrm{m}$ for a $8-\mathrm{mm}$ in diameter central area and below $40 \mu \mathrm{m}$ for an extended area of 16-mm in diameter. ${ }^{14}$ Thanks to this high accuracy, we attempted to characterise the corneo-scleral irregularities present in keratoconus as well as to evaluate the potential diagnostic value of such peculiarities for its detection.

As in previous studies, ${ }^{1,5-9}$ in our study, keratoconus corneas showed larger values of corneal curvature, astigmatism and eccentricity than healthy corneas. Correspondingly, this was associated with significantly higher levels of refractive astigmatism and poorer visual acuity. These corneal changes have been previously reported and confirmed to be in relation with the mechanical weakening of the corneal

structure. ${ }^{18}$ In contrast, no significant differences between groups were found in the mean scleral radius, best fit sphere for cornea, limbus and sclera, and in the mean corneal radius. Therefore, no differences in the average parameters of the corneo-scleral topography were found between groups. Nevertheless, local differences between groups could be present as significant asymmetries might be not detected by average values or generalized analyses. Indeed, significant differences between groups were detected in ITA, TSH11, TSH12, T-NSH12, MaxSH12, TSH13, and T-NSH13. Sorbara et al ${ }^{19}$ also 
reported using OCT technology significant differences in eye sagittal heights between normal and keratoconus eyes. In our sample, lower ITA values alongside higher sagittal heights and sagittal height differences were found in the keratoconus group, which confirms the presence of a more asymmetric corneal and anterior conjunctivo-scleral profile rather than in healthy eyes. The higher level of asymmetry found in keratoconus would explain the need for a peritoric scleral contact lens in some fittings in keratoconus. ${ }^{20}$ In agreement with our results, Mas-Aixala and coauthors ${ }^{21}$ outlined that keratoconus resulted in central and peripheral corneal manifestations, as well as changes in the shape of the scleral limbus using the corneal topographer Pentacam from Oculus.

In our sample, when the analysis was performed with the right and left eyes of bilateral keratoconus cases of keratoconus group, some differences were found. The most relevant discrepancy was the absence of statistically significant differences in almost all sclero-corneal topographic parameters between control and keratoconus groups when the left eye in this group was considered. It should be noted that the left eye was the eye with the less severe stage of the disease in all bilateral cases (most of them grade I), suggesting that only in moderate and advanced stages of the disease there is a significant presence of alterations of the sclero-conjunctival geometric profile.

Our results also suggest that the mechanical imbalance caused by the collagen disruption in keratoconus could be affecting the sclera in terms of geometry. The mechanical weakening of the cornea results in a re-adjustment of the corneal geometry and the inner forces in the corneal stroma. As a consequence, the corneal stroma is "pulling" differently from the sclera depending on the location of the keratoconus. We hypothesize that this imbalance in the inner corneal forces is causing the corneo-scleral profile to rise in areas far from the keratoconus whereas is decreasing in areas close to it. This theory is supported by the raise of the corneo-scleral profile depicted in Figure 
1. Previous studies have provided evidence of scleral structural changes and mechanical alterations in keratoconus. ${ }^{11,22,23}$ Kopaeva et $\mathrm{al}^{11}$ performed a morphologic examination of 5 trephination scleral disks in various types of corneal ectasia. They concluded that there was an involvement of the scleral connective tissue in terms of extracellular dysproteinosis, which is the morphologic substrate of deterioration of the elastic properties of the sclera. ${ }^{11}$ Likewise, other least marked changes were detected, such as the fragmentation and the fiber degeneration of collagen bundles. ${ }^{11}$ Zhou et $\mathrm{al}^{24}$ determined the stromal thickness distribution in keratoconic and healthy eyes, suggesting that the stromal thickness was generally lower in keratoconus compared with healthy eyes, while Schlatter et $\mathrm{al}^{25}$ used the same parameter differentiating in the same groups, not obtaining significant differences between both groups More studies are still required to characterise if there are really structural changes in the sclera of eyes with keratoconus or our hypothesis is confirmed. Likewise, studies with larger sample sizes are necessary to define how these structural changes if present affect to the geometry of the conjunctival-scleral surface and if, as detected preliminarily, this affectation is only clinically detectable in moderate and severe keratoconus cases.

In the group of healthy eyes, different statistically significant correlations were detected between the corneal and the scleral data, although most of them were weak. A statistically significant and moderate correlation was found between the mean corneal and scleral radius ( $\mathrm{r}: 0.403, \mathrm{p}<0.001$ ), being consistent with results in Jesus et al ${ }^{12}$ where a better correlation between the corneal and the scleral radius ( $\mathrm{r}: 0.65, \mathrm{p}<0.001)$ was found. Contrarily, no correlation between the mean corneal and scleral radius was found for the keratoconus group. The presence of a higher level of irregularity in the scleral geometry for keratoconus eyes could explain this lack of correlation, since is leading to a great variability in the scleral radius. Indeed, significantly higher values of naso- 
temporal sagittal height asymmetry were found in keratoconus. Moreover, this higher scleral irregularity for keratoconus eyes supports that most of the weak to moderate correlations found in the control group are not present in keratoconus. When the best fit sphere is used to characterise the corneal and scleral area, significant correlations were detected in both groups between the inner and the outer BFS, especially in keratoconus. This outlines that there is a more significant trend to steepening of the sclera when the cornea steepens in keratoconus. However, this trend is also associated with high levels of irregularity of the corneal surface, generating more dispersion of local curvature data and less representativeness of the average values. Future studies are necessary to confirm all these findings in larger sample sizes of keratoconus cases as well as in other types of corneal ectatic diseases.

Apart from all the aforementioned correlations, significant and good correlations were found between both groups in corneal curvature and sagittal height data, which is coherent as the radius of curvature is used to define the sagittal height of the eye. It should be remarked that the maximum sagittal height and the magnitude of corneal astigmatism presented a moderate but statistically significant correlation only in the keratoconus group. Specifically, the higher the magnitude of corneal astigmatism, the higher the maximum sagittal height for a chord of $12 \mathrm{~mm}$ was. This finding suggests that higher levels of corneal astigmatism are present in those eyes with deeper sagittal heights and is supported by results of many studies in which the magnitude of the corneal astigmatism was confirmed to increase with the level of severity of

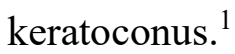

Regarding the evaluation by ROC analysis of the potential diagnostic ability of the sclero-corneal parameters for the detection of keratoconus, the best diagnostic discrimination was achieved for TSH13 and T-NSH13, with cutoff values of $2.90 \mathrm{~mm}$ 
(sensitivity $61.1 \%$, specificity $62.8 \%$ ) and $0.085 \mathrm{~mm}$ (sensitivity $61.1 \%$, specificity $57.0 \%$ ), respectively. This diagnostic ability is limited compared to the sensitivity and the specificity reported for a variety of pachymetric, topographic, aberrometric, and elevation parameters. ${ }^{1,5-9}$ Montalban et $\mathrm{al}^{26}$ found that the minimum corneal thickness presented a sensitivity of $98.4 \%$ and a specificity of $71 \%$ with a cutoff value of 525.91 $\mu \mathrm{m}$, being a reliable marker for the detection of keratoconus. Alternatively, Buhren et $\mathrm{al}^{27}$ found that the root mean square of the high order aberrations of the anterior corneal surface presented a cutoff value of $0.555 \mu \mathrm{m}$, with sensitivity and specificity values of $100 \%$ and $98.4 \%$, respectively. Oppositely, the diagnostic ability of the mean keratometry $(\mathrm{KM})$ (sensitivities $>80 \%$ and specificities $>70 \%$ for cut-off points between 45.2 $\mathrm{D}$ and 45.7 D) and topographic astigmatism (sensitivity and specificity $>75 \%$ for cut-off point of $2.5 \mathrm{D})$ were highlighted to be more limited. ${ }^{1}$ Finally, the posterior corneal elevation has been reported to have a very good ability in the detection of keratoconus, with sensitivities and specificities above $90 \%$ in most of the studies. ${ }^{1}$ In this vein, the sclero-corneal parameters measured with the ESP system presented an ability to detect keratoconus similar to the one reported for some corneal biomechanical parameters, such as the corneal hysteresis $(\mathrm{CH})$ or the corneal resistance factor $(\mathrm{CRF})$ provided by the Ocular Response Analyzer (ORA, Reichert, Germany). ${ }^{28,29}$ Touboul et $\mathrm{al}^{28}$ found that the optimal $\mathrm{CH}$ cutoff for keratoconus detection was $9.6 \mathrm{mmHg}$, with a sensitivity and a specificity of $66 \%$ and $67 \%$, respectively. In particular, we stress that the TSH13 and T-NSH13 have the potential to detect keratoconus but in combination with other pachymetric, aberrometric or biomechanical parameters. Nevertheless, future studies with larger samples of keratoconus should be conducted to develop prediction models that combine sclero-corneal data with other clinical variables. This combination has been suggested to be effective to increase the sensitivity and the specificity in 
keratoconus detection and, therefore, prediction models that are based on the combination of multiple data are the best option to optimize clinical decisions regarding the detection of keratoconus. ${ }^{1,26,30}$

This study has some limitations that should be acknowledged. First, the sample size of keratoconus cases is limited, but it allows to detect the main trends of corneoconjunctival geometry in this type of cases. Future studies with a larger number of cases should be performed in order to confirm these trends and also to evaluate the effect of different type of surgical treatments, such as corneal collagen crosslinking and the implantation of intracorneal ring segments. Second, it should be considered that instrument measurement errors commonly increase radially from the center of the anterior eye topography to its edge. Iskander et $\mathrm{al}^{14}$ demonstrated using calibrated artificial surfaces that the accuracy of measurement (in terms of root mean square error, RMS) was below $10 \mu \mathrm{m}$ for a central measurement area of $8 \mathrm{~mm}$ diameter and below $40 \mu \mathrm{m}$ for an extended measurement area of $16 \mathrm{~mm}$. In some cases, the error reached levels of up to $200 \mu \mathrm{m}$ at the very periphery of the measured surface (up to $20 \mathrm{~mm}$ ). ${ }^{14}$ However, in our study, we have only considered parameters calculated considering as much a diameter of $14 \mathrm{~mm}$ in order to avoid the potential interference of these peripheral errors. Therefore, it is expected that this increase of radial errors to the periphery has had a minimal impact on our outcomes (RMS below 30-40 $\mu \mathrm{m}$ for elevation data). Finally, although we included bilateral cases with asymmetric severity of keratoconus between fellow eyes, future studies should be conducted including one eye from different patients from a significantly larger sample. This would allow a definitive confirmation of our outcomes.

In conclusion, a higher level of asymmetry seems to be present in the corneoscleral profile of keratoconus eyes when compared to healthy eyes, suggesting that a 
potential geometric alteration exists in both the diseased cornea and the anterior sclera especially in those cases with moderate or advanced stage of the disease. This asymmetry should be considered when fitting scleral contact lenses in moderate and advanced keratoconus eyes, being the use of peritoric designs the potential first option. The detection of keratoconus in clinic cannot be done solely based on the corneo-scleral topographic data, and must be done in conjunction with other clinical parameters (or signs). As this paper has some limitations including sample size, the accuracy of the technology used and the inclusion of bilateral cases, it allows to detect trends that should be confirmed in future studies using more robust designs and even different technologies of measurement. 


\section{References}

1.- Piñero DP, Nieto JC, Lopez-Miguel A. Characterization of corneal structure in keratoconus. J Cataract Refract Surg 2012; 38: 2167-83.

2.- White TL, Lewis PN, Young RD, Kitazawa K, Inatomi T, Kinoshita S, Meek KM. Elastic microfibril distribution in the cornea: Differences between normal and keratoconic stroma. Exp Eye Res 2017; 159: 40-8.

3.- Morishige N, Shin-Gyou-Uchi R, Azumi H, Ohta H, Morita Y, Yamada N, Kimura

K, Takahara A, Sonoda KH. Quantitative analysis of collagen lamellae in the normal and keratoconic human cornea by second harmonic generation imaging microscopy. Invest Ophthalmol Vis Sci 2014; 25: 8377-85.

4.- Palka BP, Sotozono C, Tanioka H, Akama TO, Yagi N, Boote C, Young RD, Meek KM, Kinoshita S, Quantock AJ. Structural collagen alterations in macular corneal dystrophy occur mainly in the posterior stroma. Curr Eye Res 2010; 35: 580-6.

5.- Piñero DP, Pérez-Cambrodí RJ, Soto-Negro R, Ruiz-Fortes P, Artola A. Clinical utility of ocular residual astigmatism and topographic disparity vector indexes in subclinical and clinical keratoconus. Graefes Arch Clin Exp Ophthalmol 2015; 253: 2229-37.

6.- Tomidokoro A, Oshika T, Amano S, Higaki S, Maeda N, Miyata K. Changes in anterior and posterior corneal curvatures in keratoconus. Ophthalmology 2000; 107: 1328-32.

7.- de Sanctis U, Loiacono C, Richiardi L, Turco D, Mutani B, Grignolo FM. Sensitivity and specificity of posterior corneal elevation measured by Pentacam in discriminating keratoconus/subclinical keratoconus. Ophthalmology 2015; 115: 1534-9. 
8.- Alió JL, Piñero DP, Alesón A, Teus MA, Barraquer RI, Murta J, Maldonado MJ, Castro de Luna G, Gutiérrez R, Villa C, Uceda-Montanes A. Keratoconus-integrated characterization considering anterior corneal aberrations, internal astigmatism, and corneal biomechanics. J Cataract Refract Surg 2011; 37: 552-68.

9.- Pinero DP, Alio JL, Aleson A, Escaf Vergara M, Miranda M. Corneal volume, pachymetry, and correlation of anterior and posterior corneal shape in subclinical and different stages of clinical keratoconus. J Cataract Refract Surg 2010; 36: 814-25.

10.- Choi S, Lee SC, Lee HJ, Cheong Y, Jung GB, Jin KH, Park HK. Structural response of human corneal and scleral tissues to collagen cross-linking treatment with riboflavin and ultraviolet A light. Lasers Med Sci 2013; 28: 1289-96.

11.- Kopaeva VG, Zatulina NI, Legkikh LS. [Clinical and morphological aspects of the state of the sclera in various types of genetically determined corneal changes]. Vestn Oftalmol 1992; 108: 17-9.

12.- Jesus DA, Kedzia R, Iskander DR. Precise measurement of scleral radius using anterior eye profilometry. Cont Lens Anterior Eye 2017; 40: 47-52.

13.- DeNaeyer G, Sanders DR. sMap3D corneo-scleral topographer repeatability in scleral lens patients. Eye Contact Lens 2017 Jul 21. doi: 10.1097/ICL.0000000000000401. [Epub ahead of print]

14.- Iskander DR, Wachel P, Simpson PN, Consejo A, Jesus DA. Principles of operation, accuracy and precision of Eye Surface Profiler. Ophthalmic Physiol Opt 2016; 36: 266-78.

15.- Consejo A, Llorens-Quintana C, Radhakrishnan H, Iskander DR. Mean shape of the human limbus. J Cataract Refract Surg 2017; 43: 667-72.

16.- Consejo A, Iskander DR. Corneo-scleral limbus demarcation from 3D height data. Cont Lens Anterior Eye 2016; 39: 450-7. 
17.- Consejo A, Radhakrishnan H, Iskander DR. Scleral changes with accommodation. Ophthalmic Physiol Opt 2017; 37: 263-74.

18.- Piñero DP, Alio JL, Barraquer RI, Michael R, Jiménez R. Corneal biomechanics, refraction, and corneal aberrometry in keratoconus: an integrated study. Invest Ophthalmol Vis Sci 2010; 51: 1948-55.

19.- Sorbara L, Maram J, Mueller K. Use of the Visante ${ }^{\mathrm{TM}}$ OCT to measure the sagittal depth and scleral shape of keratoconus compared to normal corneas: Pilot study. J Optom 2013; 6: 141-6.

20.- Piñero DP, Soto-Negro R. Anterior eye profilometry-guided scleral contact lens fitting in keratoconus: a case report. Int J Kerat Corn Ect Dis 2017; 6: 1-4.

21.- Mas-Aixala E, Gispets J, Lupón N, Cardona G. The variability of corneal and anterior segment parameters in keratoconus. Cont Lens Anterior Eye 2016; 39: 466-70.

22.- Choi S, Lee SC, Lee HJ, Cheong Y, Jung GB, Jin KH, Park HK. Structural response of human corneal and scleral tissues to collagen cross-linking treatment with riboflavin and ultraviolet A light. Lasers Med Sci 2013; 28: 1289-96.

23.- Edmund C. Corneal elasticity and ocular rigidity in normal and keratoconic eyes. Acta Ophthalmol (Copenh) 1988; 66: 134-40.

24.- Zhou W, Stojanovic A. Comparison of corneal epithelial and stromal thickness distributions between eyes with keratoconus and healthy eyes with corneal astigmatism $>2.0$ D. PLoS One 2014; 9(1): e85994.

25.- Schlatter B, Beck M, Frueh BE, Tappeiner C. Evaluation of scleral and corneal thickness in keratoconus patients. J Cataract Refract Surg 2014; 41: 1073-80.

26.- Montalbán R, Alio JL, Javaloy J, Piñero DP. Comparative analysis of the relationship between anterior and posterior corneal shape analyzed by Scheimpflug 
photography in normal and keratoconus eyes. Graefes Arch Clin Exp Ophthalmol 2013; 251: 1547-55.

27.- Buhren J, Kuhne C, Kohnen T. Defining subclinical keratoconus using corneal first-surface higher-order aberrations. Am J Ophthalmol 2007; 143: 381-9.

28.- Touboul D, Benard A, Mahmoud AM, Gallois A, Colin J, Roberts CJ. Early biomechanical keratoconus pattern measured with an ocular response analyzer: curve analysis. J Cataract Refract Surg 2011; 37: 2144-50.

29.- Shah S, Laiquzzaman M, Bhojwani R, Mantry S, Cunliffe I. Assessment of the biomechanical properties of the cornea with the ocular response analyzer in normal and keratoconic eyes. Invest Ophthalmol Vis Sci 2007; 48: 3026-31.

30.- Arbelaez MC, Versaci F, Vestri G, Barboni P, Savini G. Use of a support vector machine for keratoconus and subclinical keratoconus detection by topographic and tomographic data. Ophthalmology 2012; 119: 2231-8. 


\section{Figure legends}

Figure 1.- Screenshot of the main screen of the software associated to the Eye Surface Profiler (ESP). It shows a summary of the results obtained in a healthy eye from our sample.

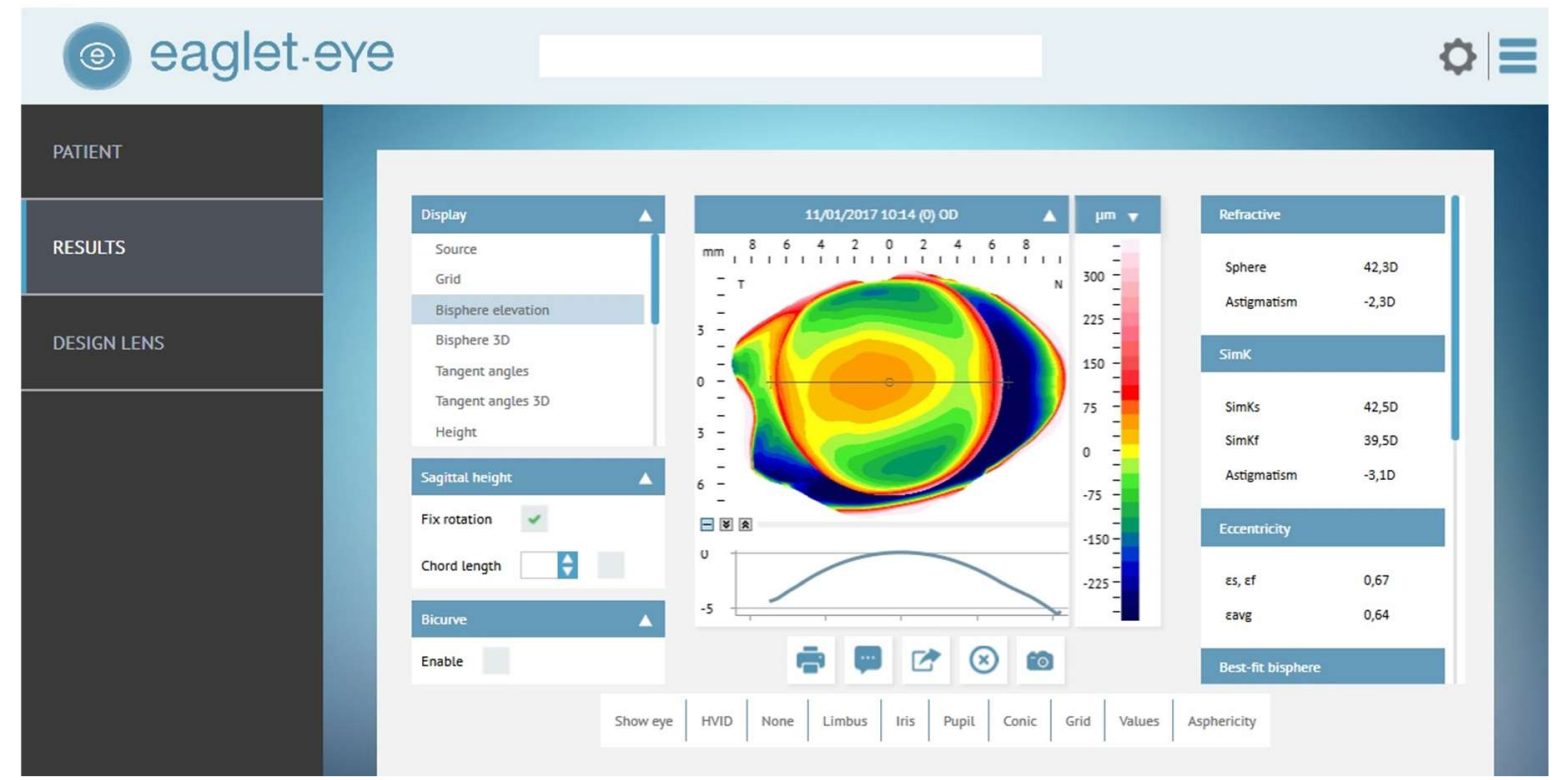


Figure 2.- Bi-sphere elevation map for a keratoconus (left) and a healthy eye (right) obtained with the ESP profiler. The corneo-scleral profile of keratoconus presents an asymmetry between nasal and temporal sagittal heights.
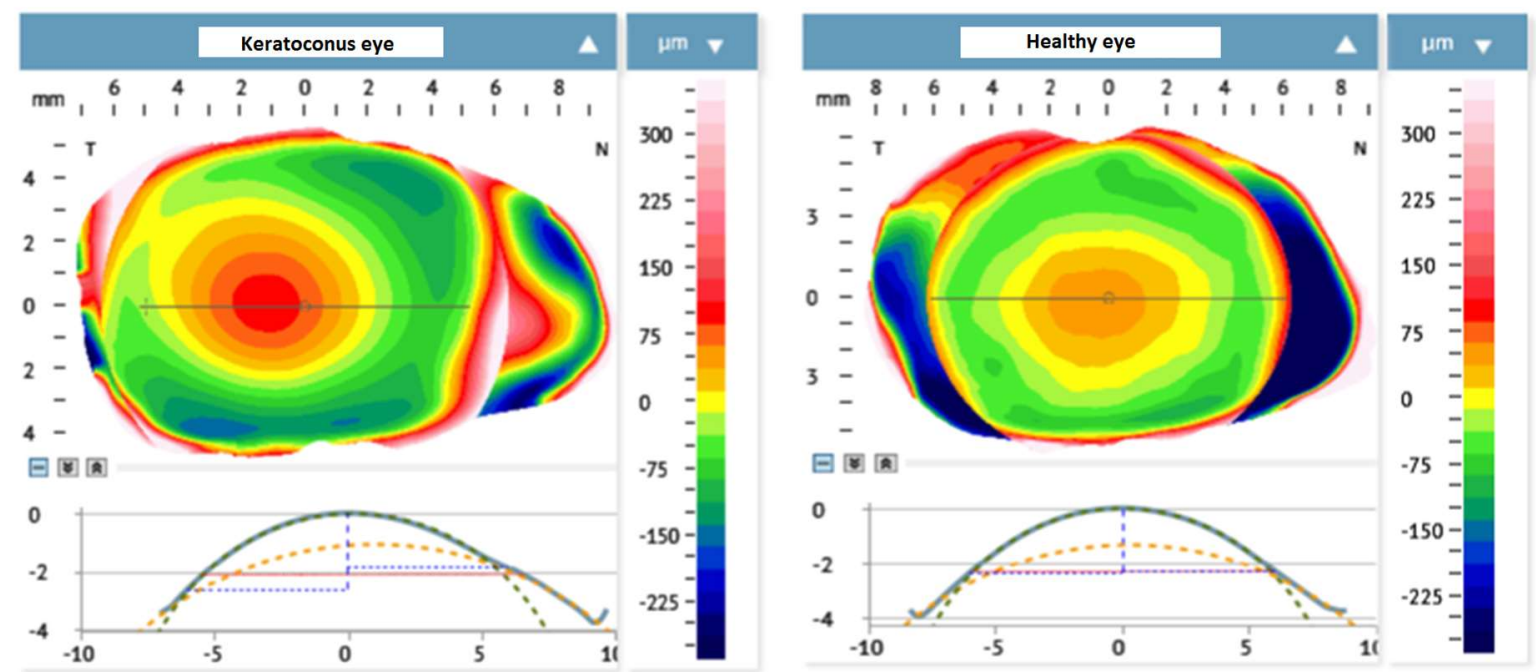
Figure 3.- Diagram showing the meaning of different anatomical variables used in the current study. BFSi: inner best fit sphere; BFSo: outer best fit sphere; TSH: temporal sagittal height; NSH: nasal sagittal height; NTA: nasal tangent angle at limbus; TTA: temporal tangent angle at limbus.

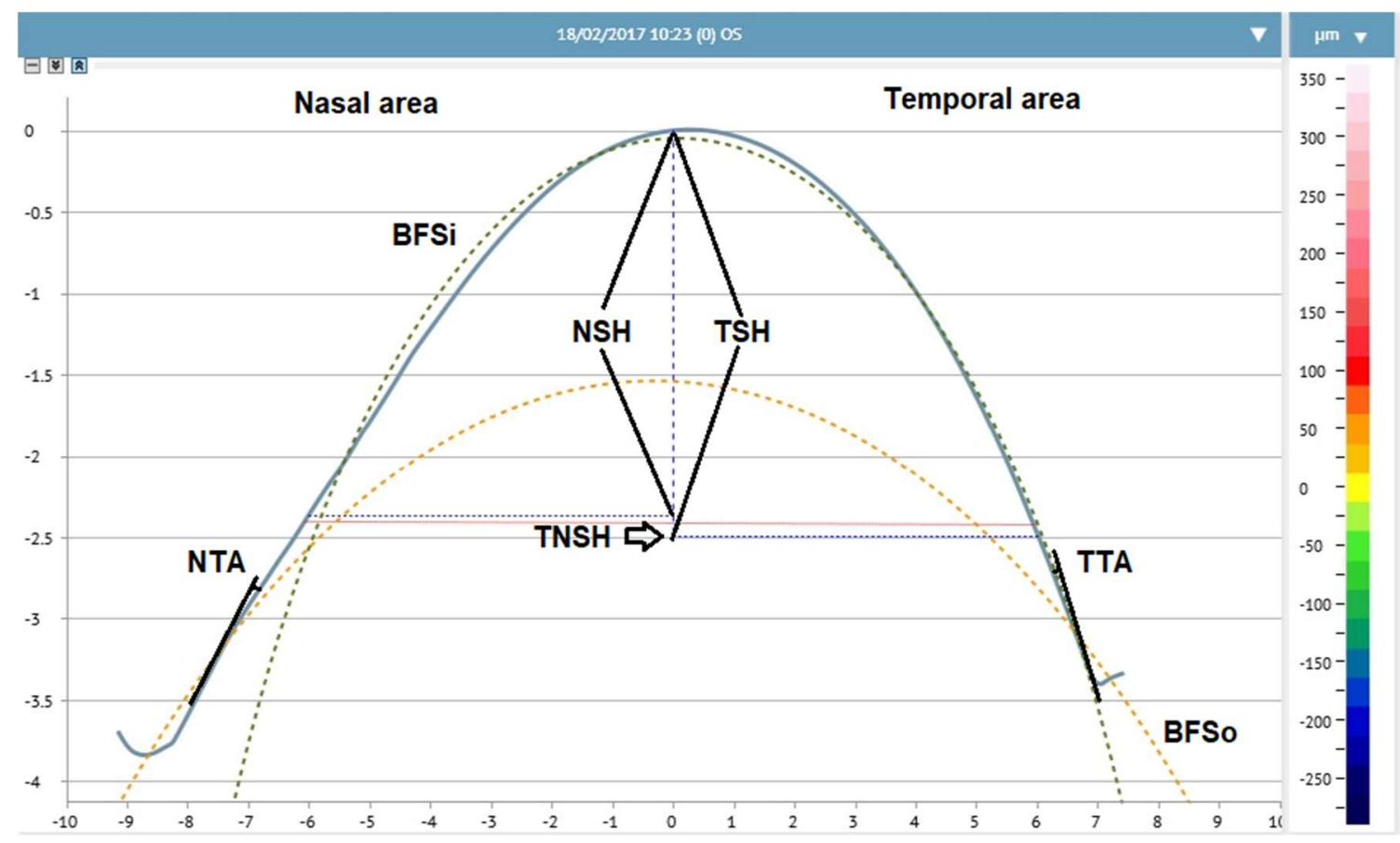


Figure 4.- Linear correlation and scattered clinical data for the outer (BFSo) and limbal best fit sphere (BFSl) in the control (up) and keratoconus groups (down).
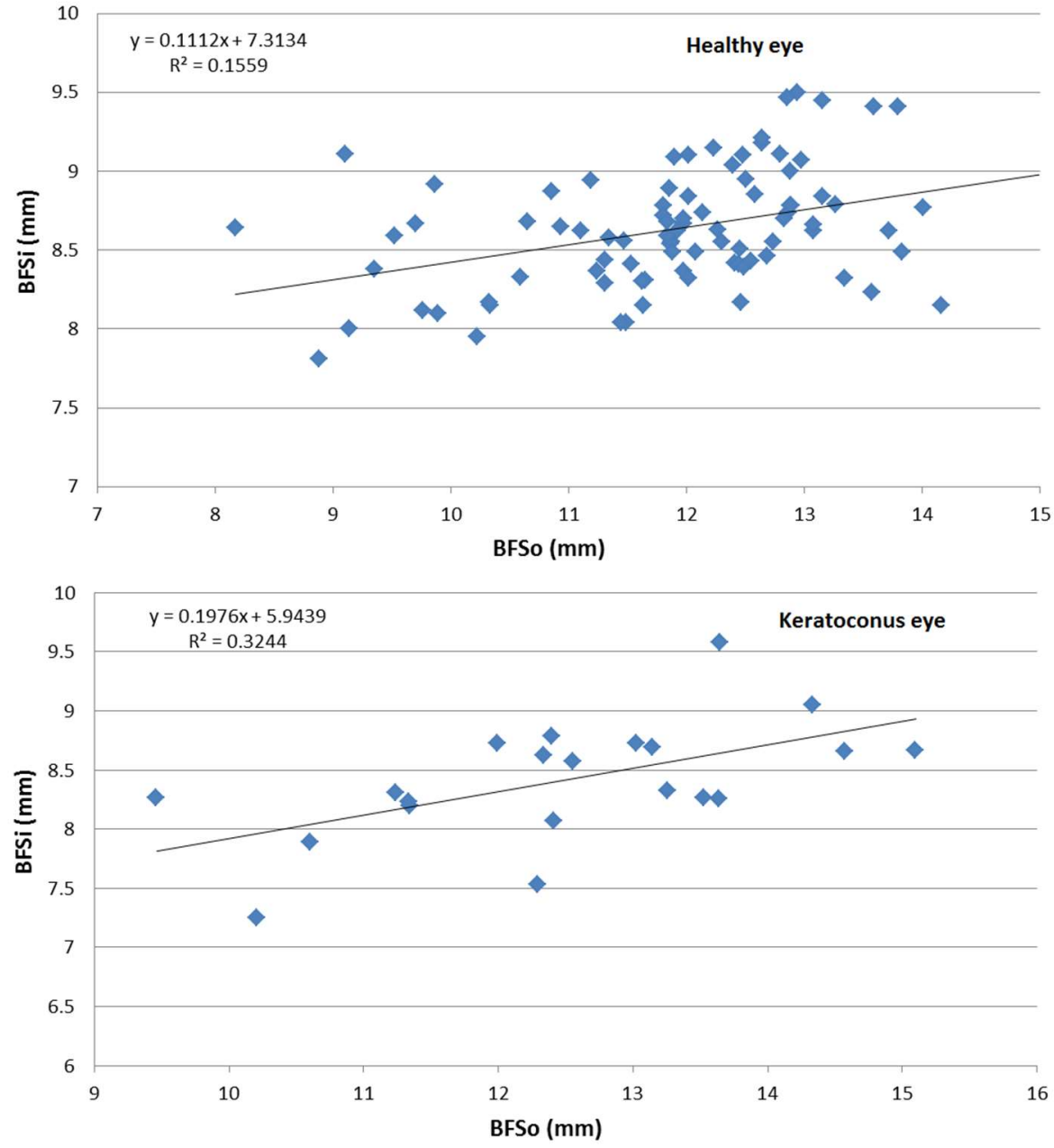
Figure 5.- Linear correlation and scattered clinical data for the outer (BFSo) and inner best fit sphere (BFSi) in the control (up) and keratoconus groups (down).
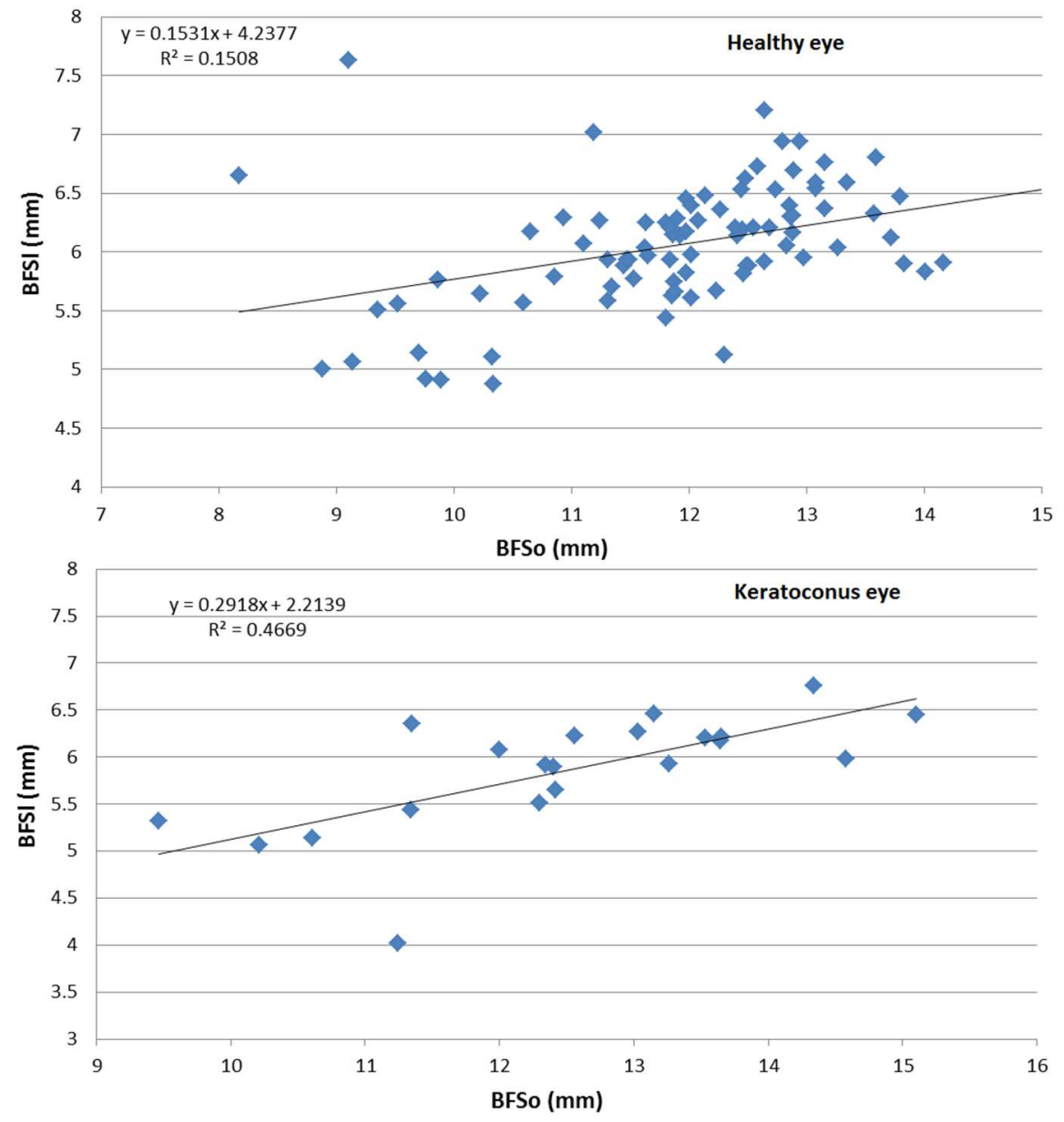
Figure 6.- Receiver operating characteristic (ROC) curves obtained for the inferior tangent angle at limbus (ITA), the temporal sagittal heights for chords of 11 (TSH11), 12 (TSH12) and $13 \mathrm{~mm}$ (TSH13), the difference between temporal and nasal sagittal heights for chords of 12 (T-NSH12) and $13 \mathrm{~mm}$ (T-NSH13), and the maximum sagittal height for a chord of $12 \mathrm{~mm}$ (MaxSH12) as predictors of the presence of keratoconus.
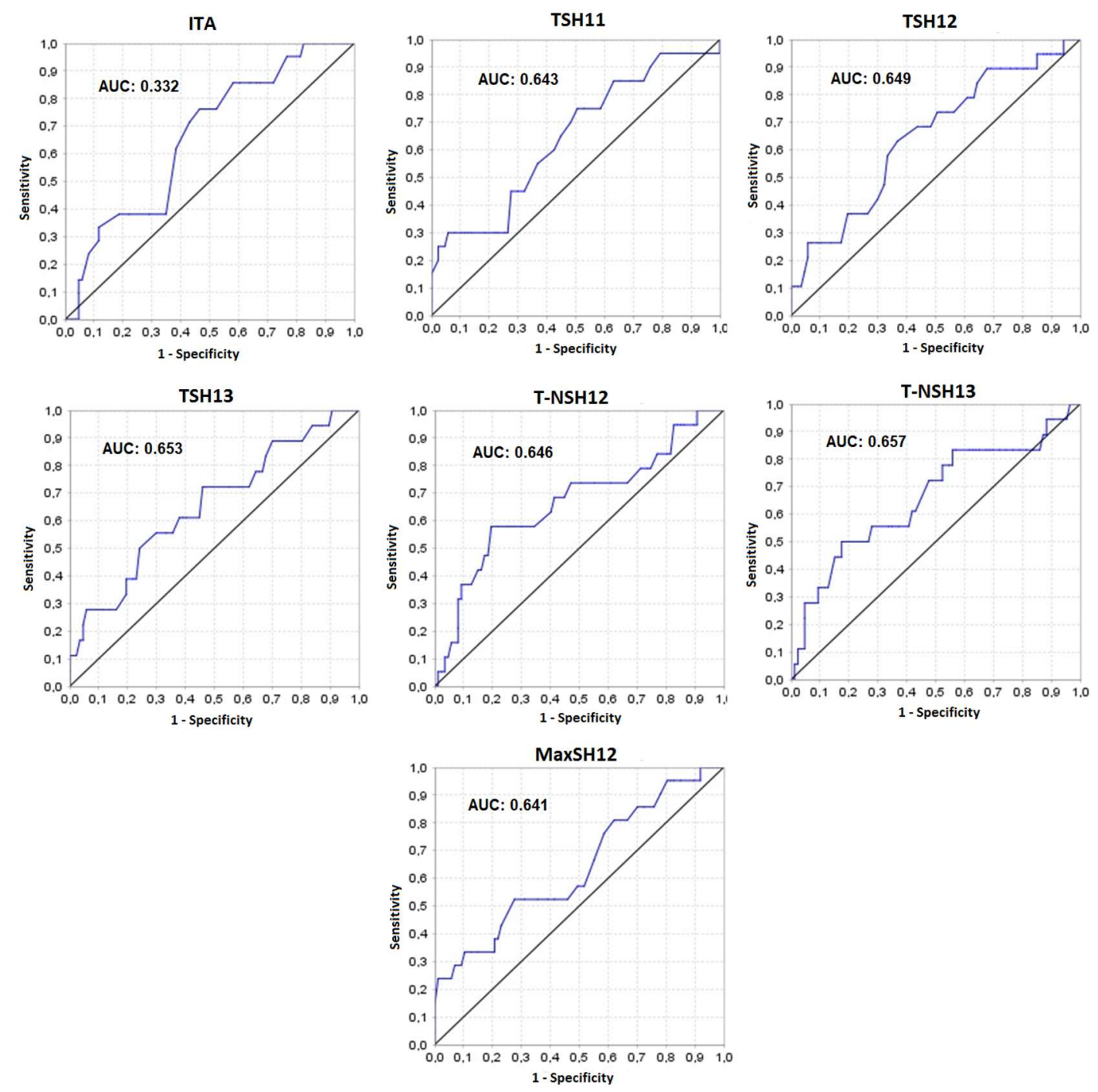


\begin{tabular}{|c|c|c|c|}
\hline $\begin{array}{c}\text { Mean (SD) } \\
\text { Median (Range) }\end{array}$ & $\begin{array}{c}\text { Control group } \\
\text { (88 eyes) }\end{array}$ & $\begin{array}{c}\text { Keratoconus group } \\
\text { (21 eyes) }\end{array}$ & p-value \\
\hline $\begin{array}{c}\text { Gender (\% } \\
\text { male/female) }\end{array}$ & $47.7 \% / 52.3 \%$ & $72.7 \% / 27.3 \%$ & 0.104 \\
\hline Eye (\% right/left) & $77.3 \% / 22.7 \%$ & $52.4 \% / 47.6 \%$ & 0.030 \\
\hline Age (years) & $38.2(13.5)$ & $39.8(8.1)$ & 0.478 \\
& $38.0(21$ to 73$)$ & $38.0(27$ to 53$)$ & 0.175 \\
\hline Sphere (D) & $-1.05(2.45)$ & $-1.00(3.38)$ & $<0.001$ \\
\hline Cylinder (D) & $0.00(-8.00$ to 5.25$)$ & $0.25(-9.50$ to 3.00$)$ & $-2.62(2.25)$ \\
& $-0.63(1.01)$ & $-2.25(-7.75$ to 0.00$)$ & \\
\hline SE (D) & $-1.36(2.37)$ & $-2.31(3.35)$ & 0.156 \\
& $-0.50(-8.50$ to 3.50$)$ & $-0.50(-11.00$ to 0.75$)$ & \\
\hline LogMAR BCDVA & $0.00(0.02)$ & $0.15(0.26)$ & $<0.001$ \\
& $0.00(0.00$ to 0.15$)$ & $0.02(0.00$ to 1.00$)$ & \\
\hline
\end{tabular}

Table 1. Summary of demographic, visual, and refractive data in keratoconus and control groups. Abbreviations: SD, standard deviation; SE, spherical equivalent; BCDVA, best corrected distance visual acuity. 


\begin{tabular}{|c|c|c|c|c|c|c|c|}
\hline \multirow[t]{2}{*}{$\begin{array}{c}\text { Mean (SD) } \\
\text { Median (Range) }\end{array}$} & \multirow{2}{*}{$\begin{array}{c}\begin{array}{c}\text { Control group } \\
\text { (88 eyes, } 88 \text { patients) }\end{array} \\
\text { Global }\end{array}$} & \multicolumn{3}{|c|}{$\begin{array}{l}\text { Keratoconus group } \\
\text { (21 eyes, } 11 \text { patients) }\end{array}$} & \multicolumn{3}{|c|}{ p-value } \\
\hline & & Right eye & Left eye & Global & $\begin{array}{l}\text { Right } \\
\text { eye }\end{array}$ & Left eye & Global \\
\hline$\overline{S i m K s ~(D) ~}$ & $\begin{array}{c}43.84(1.53) \\
43.80(39.20 \text { to } 47.10)\end{array}$ & $\begin{array}{c}54.09(6.80) \\
52.50(43.50 \text { to } 67.50)\end{array}$ & $\begin{array}{c}50.65(7.86) \\
49.40(41.60 \text { to } 67.50)\end{array}$ & $\begin{array}{c}51.14(7.17) \\
49.80(41.60 \text { to } 67.50)\end{array}$ & $<0.001$ & 0.001 & $<0.001$ \\
\hline SimKf (D) & $\begin{array}{c}42.33(1.76) \\
42.50(35.80 \text { to } 46.50)\end{array}$ & $\begin{array}{c}47.29(4.88) \\
47.70(41.50 \text { to } 56.80)\end{array}$ & $\begin{array}{c}46.64(7.38) \\
43.60(41.00 \text { to } 62.30)\end{array}$ & $\begin{array}{c}46.21(5.62) \\
44.20(41.00 \text { to } 62.30)\end{array}$ & 0.001 & 0.207 & 0.001 \\
\hline$\overline{\mathrm{e}}$ & $\begin{array}{c}0.71(0.17) \\
0.68(0.31 \text { to } 1.27)\end{array}$ & $\begin{array}{c}1.11(0.35) \\
1.05(0.63 \text { to } 1.57)\end{array}$ & $\begin{array}{c}1.00(0.26) \\
1.07(0.62 \text { to } 1.41)\end{array}$ & $\begin{array}{c}0.98(0.33) \\
1.04(0.51 \text { to } 1.57)\end{array}$ & 0.001 & 0.099 & 0.001 \\
\hline BFSi (mm) & $\begin{array}{c}8.71(0.37) \\
8.62(7.81 \text { to } 9.50)\end{array}$ & $\begin{array}{c}8.36(0.52) \\
8.33(7.25 \text { to } 9.05)\end{array}$ & $\begin{array}{c}8.50(0.58) \\
8.44(7.53 \text { to } 9.58)\end{array}$ & $\begin{array}{c}8.41(0.50) \\
8.33(7.25 \text { to } 9.58)\end{array}$ & 0.229 & 0.092 & 0.053 \\
\hline BFSI (mm) & $\begin{array}{c}6.06(0.52) \\
6.10(4.88 \text { to } 7.63)\end{array}$ & $\begin{array}{c}6.03(0.48) \\
6.08(5.06 \text { to } 6.76)\end{array}$ & $\begin{array}{c}5.75(0.79) \\
6.06(4.02 \text { to } 6.46)\end{array}$ & $\begin{array}{c}5.86(0.62) \\
5.98(4.02 \text { to } 6.76)\end{array}$ & 0.889 & 0.098 & 0.323 \\
\hline HVID (mm) & $\begin{array}{c}12.09(0.43) \\
12.07(10.97 \text { to } 12.62)\end{array}$ & $\begin{array}{c}12.13(0.30) \\
12.25(11.52 \text { to } 12.62)\end{array}$ & $\begin{array}{c}12.25(0.47) \\
12.44(11.34 \text { to } 12.62)\end{array}$ & $\begin{array}{c}12.23(0.36) \\
12.25(11.34 \text { to } 12.62)\end{array}$ & 0.737 & 0.115 & 0.206 \\
\hline$r_{c}(\mathrm{~mm})$ & $\begin{array}{c}8.54(0.38) \\
8.48(7.86 \text { to } 9.66)\end{array}$ & $\begin{array}{c}8.18(0.35) \\
7.97(7.80 \text { to } 8.67)\end{array}$ & $\begin{array}{c}8.50(0.51) \\
8.47(7.82 \text { to } 9.50)\end{array}$ & $\begin{array}{c}8.36(0.41) \\
8.41(7.80 \text { to } 9.50)\end{array}$ & 0.022 & 0.824 & 0.085 \\
\hline $\mathbf{r}_{\mathrm{s}}(\mathrm{mm})$ & $\begin{array}{c}13.35(1.29) \\
13.25(11.05 \text { to } 17.31)\end{array}$ & $\begin{array}{c}14.03(1.31) \\
13.99(11.69 \text { to } 16.10)\end{array}$ & $\begin{array}{c}12.69(0.53) \\
12.61(12.14 \text { to } 13.58)\end{array}$ & $\begin{array}{c}13.40(1.21) \\
13.12(11.69 \text { to } 16.10)\end{array}$ & 0.106 & 0.140 & 0.871 \\
\hline NTA $\left(^{\circ}\right)$ & $\begin{array}{c}35.31(6.55) \\
37.00(12 \text { to } 47)\end{array}$ & $\begin{array}{c}32.89(6.01) \\
29.00(27 \text { to } 44)\end{array}$ & $\begin{array}{c}32.25(7.78) \\
29.50(23 \text { to } 44)\end{array}$ & $\begin{array}{c}32.95(6.24) \\
30.00(23 \text { to } 44)\end{array}$ & 0.085 & 0.301 & 0.062 \\
\hline TTA $\left(^{\circ}\right)$ & $\begin{array}{c}38.76(5.90) \\
40.00(21 \text { to } 51)\end{array}$ & $\begin{array}{c}44.11(7.13) \\
46.00(31 \text { to } 52)\end{array}$ & $\begin{array}{c}41.38(7.96) \\
41.50(30 \text { to } 53)\end{array}$ & $\begin{array}{c}41.67(8.14) \\
44.00(25 \text { to } 53)\end{array}$ & 0.024 & 0.672 & 0.066 \\
\hline STA $\left(^{\circ}\right)$ & $\begin{array}{c}32.76(7.04) \\
35.00(15 \text { to } 44)\end{array}$ & $\begin{array}{c}26.89(10.69) \\
27.00(7 \text { to } 41)\end{array}$ & $\begin{array}{c}29.75(10.47) \\
26.50(16 \text { to } 51)\end{array}$ & $\begin{array}{c}29.52(10.33) \\
27.00(7 \text { to } 51)\end{array}$ & 0.479 & 0.057 & 0.083 \\
\hline ITA $\left(^{\circ}\right)$ & $\begin{array}{c}25.91(8.99) \\
25.00(3 \text { to } 43)\end{array}$ & $\begin{array}{c}24.22(8.42) \\
22.00(11 \text { to } 35)\end{array}$ & $\begin{array}{c}18.25(6.50) \\
20.00(9 \text { to } 26)\end{array}$ & $\begin{array}{c}20.95(7.44) \\
22.00(9 \text { to } 35)\end{array}$ & 0.224 & 0.029 & 0.024 \\
\hline
\end{tabular}

Table 2. Summary of corneo-scleral topographic data in keratoconus and control groups. Abbreviations: SD, standard deviation; SimKs, steepest simulated keratometric reading. SimKf flattest simulated keratometric reading; Ast, corneal astigmatism; e, corneal eccentricity; BFSi, inner best fit sphere; BFSl, limbus best fit sphere; BFSo, outer best fit sphere; HVID, horizontal visible iris diameter; $\mathrm{r}_{\mathrm{c}}$, mean corneal radius; $\mathrm{r}_{\mathrm{s}}$, mean scleral radius; NTA, nasal tangent angle at limbus; TTA, temporal tangent angle at limbus; STA, superior tangent angle at limbus; ITA, inferior tangent angle at limbus. 


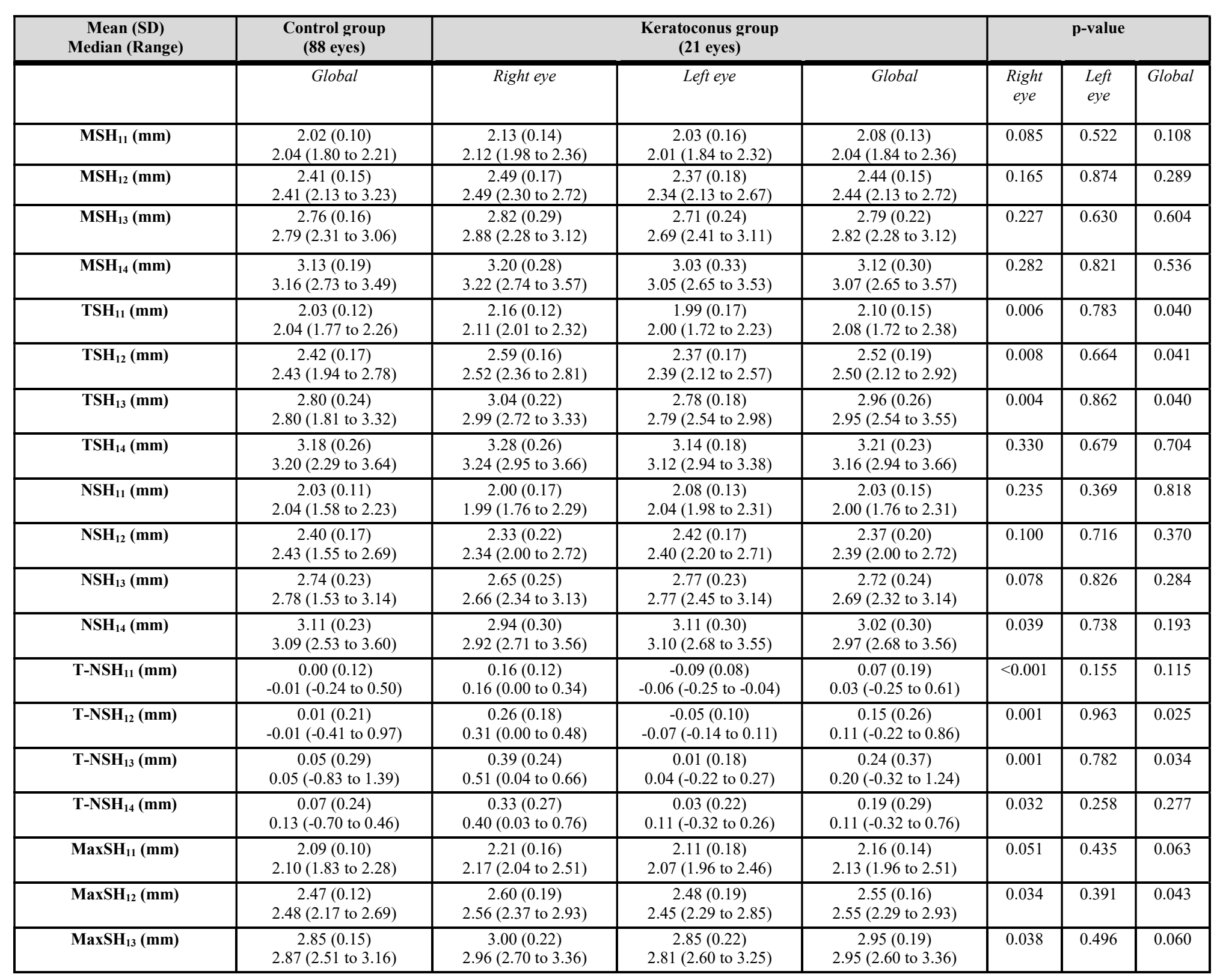




\begin{tabular}{|c|c|c|c|c|c|c|c|}
\hline $\mathrm{MaxSH}_{14}(\mathrm{~mm})$ & $\begin{array}{c}3.22(0.18) \\
3.25(2.73 \text { to } 3.53)\end{array}$ & $\begin{array}{c}3.35(0.32) \\
3.29(2.80 \text { to } 3.81)\end{array}$ & $\begin{array}{c}3.21(0.26) \\
3.16(2.88 \text { to } 3.66)\end{array}$ & $\begin{array}{c}3.28(0.29) \\
3.25(2.80 \text { to } 3.81)\end{array}$ & 0.122 & 0.758 & 0.195 \\
\hline $\mathrm{MinSH}_{11}(\mathrm{~mm})$ & $\begin{array}{c}1.87(0.16) \\
1.87(1.39 \text { to } 2.15)\end{array}$ & $\begin{array}{c}1.93(0.12) \\
1.89(1.84 \text { to } 2.21)\end{array}$ & $\begin{array}{c}1.87(0.14) \\
1.86(1.73 \text { to } 2.08)\end{array}$ & $\begin{array}{c}1.91(0.12) \\
1.92(1.72 \text { to } 2.21)\end{array}$ & 0.216 & 0.534 & 0.207 \\
\hline $\mathrm{MinSH}_{12}(\mathrm{~mm})$ & $\begin{array}{c}2.20(0.19) \\
2.21(1.65 \text { to } 2.55)\end{array}$ & $\begin{array}{c}2.20(0.19) \\
2.20(1.99 \text { to } 2.59)\end{array}$ & $\begin{array}{c}2.02(0.23) \\
2.08(1.59 \text { to } 2.27)\end{array}$ & $\begin{array}{c}2.15(0.20) \\
2.14(1.59 \text { to } 2.59)\end{array}$ & 0.876 & 0.227 & 0.494 \\
\hline $\mathrm{MinSH}_{13}(\mathrm{~mm})$ & $\begin{array}{c}2.53(0.22) \\
2.55(1.93 \text { to } 2.92)\end{array}$ & $\begin{array}{c}2.50(0.29) \\
2.59(1.97 \text { to } 2.90)\end{array}$ & $\begin{array}{c}2.41(0.39) \\
2.37(1.80 \text { to } 2.94)\end{array}$ & $\begin{array}{c}2.48(0.29) \\
2.53(1.80 \text { to } 2.94)\end{array}$ & 0.713 & 0.255 & 0.623 \\
\hline $\operatorname{MinSH}_{14}(\mathrm{~mm})$ & $\begin{array}{c}2.88(0.32) \\
2.89(1.45 \text { to } 3.32)\end{array}$ & $\begin{array}{c}2.98(0.20) \\
2.94(2.70 \text { to } 3.35)\end{array}$ & $\begin{array}{c}2.72(0.71) \\
2.86(1.41 \text { to } 3.46)\end{array}$ & $\begin{array}{c}2.86(0.50) \\
2.93(1.41 \text { to } 3.46)\end{array}$ & 0.468 & 0.806 & 0.326 \\
\hline
\end{tabular}

Table 3. Summary of sagittal height data in keratoconus and control groups. Abbreviations: $\mathrm{SD}$, standard deviation; $\mathrm{MSH}_{11}, \mathrm{MSH}_{12}, \mathrm{MSH}_{13}$, and $\mathrm{MSH}_{14}$, mean sagittal height for a chord of $11,12,13$ and 14 mm; TSH ${ }_{11}$, TSH 2 , TSH $\mathrm{NSH}_{12}, \mathrm{NSH}_{13}$, and $\mathrm{NSH}_{14}$, temporal and nasal sagittal height for the same chords; T- $\mathrm{NSH}_{11}, \mathrm{~T}-\mathrm{NSH}_{12}, \mathrm{~T}-\mathrm{NSH}_{13}$, and T- $\mathrm{NSH}_{14}$, difference between temporal and nasal sagittal heights for the same chords; $\mathrm{MaxSH}_{11}$, $\mathrm{MaxSH}_{12}$, MaxSH $\mathrm{Min}_{13}, \mathrm{MaxSH}_{14}$, 


\begin{tabular}{|c|c|c|}
\hline $\begin{array}{l}\text { Relationship } \\
\text { (r, p-value) }\end{array}$ & $\begin{array}{l}\text { Control group } \\
\text { (88 eyes) }\end{array}$ & $\begin{array}{c}\text { Keratoconus group } \\
\text { (21 eyes) }\end{array}$ \\
\hline $\begin{array}{c}\mathbf{r}_{\mathbf{s}}(\mathbf{m m}) \text { with: } \\
r_{c}(\mathrm{~mm}) \\
B F S_{i}(\mathrm{~mm}) \\
\operatorname{SimKf}(\mathrm{D}) \\
\text { Ast }(D) \\
\end{array}$ & $\begin{array}{l}\text { r: } 0.403, \mathrm{p}<0.0001 \\
\text { r: } 0.359, \mathrm{p}: 0.001 \\
\text { r: }-0.329, \mathrm{p}: 0.003 \\
\mathrm{r}:-0.276, \mathrm{p}: 0.015\end{array}$ & $\begin{array}{l}\text { r: }-0.039, \mathrm{p}: 0.881 \\
\text { r: } 0.189, \mathrm{p}: 0.468 \\
\mathrm{r}: 0.020, \mathrm{p}: 0.940 \\
\mathrm{r}:-0.020, \mathrm{p}: 0.940\end{array}$ \\
\hline $\begin{array}{c}\text { T-NSH }_{12} \text { (mm) with: } \\
e\end{array}$ & $\mathrm{r}:-0.342, \mathrm{p}: 0.001$ & $\mathrm{r}:-0.202, \mathrm{p}: 0.407$ \\
\hline $\begin{array}{c}\text { T-NSH } \\
e_{13} \text { (mm) with: } \\
e\end{array}$ & $\mathrm{r}:-0.352, \mathrm{p}: 0.001$ & $\mathrm{r}:-0.183, \mathrm{p}: 0.467$ \\
\hline $\begin{array}{c}\text { NTA }\left(^{\mathbf{o}}\right) \text { with: } \\
r_{c}(\mathrm{~mm}) \\
B F S_{i}(\mathrm{~mm})\end{array}$ & $\begin{array}{l}\mathrm{r}:-0.256, \mathrm{p}: 0.016 \\
\mathrm{r}:-0.268, \mathrm{p}: 0.012\end{array}$ & $\begin{array}{l}\text { r: }-0.022, p: 0.925 \\
\text { r: }-0.127, p: 0.582\end{array}$ \\
\hline $\begin{array}{c}\text { TTA }\left(^{\mathbf{o}}\right) \text { with: } \\
r_{c}(\mathrm{~mm}) \\
B F S_{i}(\mathrm{~mm}) \\
\operatorname{SimKs}_{(\mathrm{D})} \\
\operatorname{SimKf}_{(\mathrm{D})} \\
e \\
\end{array}$ & $\begin{array}{l}\text { r: }-0.334, \mathrm{p}: 0.001 \\
\mathrm{r}:-0.245, \mathrm{p}: 0.022 \\
\mathrm{r}: 0.244, \mathrm{p}: 0.022 \\
\mathrm{r}: 0.259, \mathrm{p}: 0.015 \\
\mathrm{r}:-0.338, \mathrm{p}: 0.001\end{array}$ & $\begin{array}{l}\text { r: }-0.427, \mathrm{p}: 0.044 \\
\text { r: }-0.125, \mathrm{p}: 0.589 \\
\text { r: } 0.285, \mathrm{p}: 0.210 \\
\text { r: } 0.292, \mathrm{p}: 0.199 \\
\text { r: }-0.100, \mathrm{p}: 0.665\end{array}$ \\
\hline $\begin{array}{c}\text { ITA }\left({ }^{\circ}\right) \text { with: } \\
e\end{array}$ & $\mathrm{r}:-0.358, \mathrm{p}: 0.001$ & $\mathrm{r}:-0.045, \mathrm{p}: 0.848$ \\
\hline 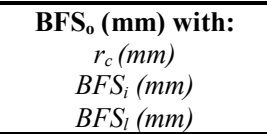 & $\begin{array}{c}\mathrm{r}: 0.275, \mathrm{p}: 0.009 \\
\mathrm{r}: 0.399, \mathrm{p}<0.0001 \\
\mathrm{r}: 0.467, \mathrm{p}<0.0001\end{array}$ & $\begin{array}{l}\text { r: } 0.032, p: 0.891 \\
\text { r: } 0.567, p: 0.007 \\
\text { r: } 0.726, p<0.0001\end{array}$ \\
\hline $\begin{array}{c}\mathbf{T S H}_{\mathbf{1 2}} \text { (mm) with: } \\
r_{c}(\mathrm{~mm}) \\
B F S_{i}(\mathrm{~mm}) \\
\operatorname{SimKs}_{\mathrm{Sim}}(\mathrm{D}) \\
\operatorname{SimKf}_{(D)} \\
e\end{array}$ & $\begin{array}{c}\mathrm{r}:-0.808, \mathrm{p}<0.001 \\
\mathrm{r}:-0.638, \mathrm{p}<0.0001 \\
\mathrm{r}: 0.581, \mathrm{p}<0.0001 \\
\mathrm{r}: 0.676, \mathrm{p}<0.0001 \\
\mathrm{r}:-0.393, \mathrm{p}<0.0001\end{array}$ & $\begin{array}{l}\text { r: }-0.777, \mathrm{p}<0.001 \\
\text { r: }-0.345, \mathrm{p}: 0.148 \\
\text { r: } 0.391, \mathrm{p}: 0.098 \\
\text { r: } 0.545, \mathrm{p}: 0.016 \\
\text { r: }-0.042, \mathrm{p}: 0.865\end{array}$ \\
\hline $\begin{array}{c}\mathbf{M a x S H}_{\mathbf{1 2}}(\mathbf{m m}) \text { with: } \\
r_{c}(\mathrm{~mm}) \\
B F S_{i}(\mathrm{~mm}) \\
\operatorname{SimKs}_{(D)} \\
\operatorname{SimKf}_{(\mathrm{D})} \\
\operatorname{Ast}(\mathrm{D}) \\
e \\
\end{array}$ & $\begin{array}{c}\mathrm{r}:-0.843, \mathrm{p}<0.001 \\
\mathrm{r}:-0.783, \mathrm{p}<0.0001 \\
\mathrm{r}: 0.701, \mathrm{p}<0.0001 \\
\mathrm{r}: 0.760, \mathrm{p}<0.0001 \\
\mathrm{r}: 0.166, \mathrm{p}: 0.123 \\
\mathrm{r}:-0.404, \mathrm{p}<0.0001\end{array}$ & $\begin{array}{c}\mathrm{r}:-0.773, \mathrm{p}<0.001 \\
\mathrm{r}:-0.748, \mathrm{p}<0.0001 \\
\mathrm{r}: 0.716, \mathrm{p}<0.0001 \\
\mathrm{r}: 0.739, \mathrm{p}<0.0001 \\
\mathrm{r}:-0.434, \mathrm{p}: 0.049 \\
\mathrm{r}: 0.318, \mathrm{p}: 0.160\end{array}$ \\
\hline
\end{tabular}


Table 4. Correlations between scleral and corneal data in keratoconus and control groups. Abbreviations: SD, standard deviation; SimKs, steepest simulated keratometric reading; SimKf, flattest simulated keratometric reading; Ast, corneal astigmatism; e, corneal eccentricity; BFSi, inner best fit sphere; BFSl, limbus best fit sphere; BFSo, outer best fit sphere; HVID, horizontal visible iris diameter; $\mathrm{r}_{\mathrm{c}}$, mean corneal radius; $\mathrm{r}_{\mathrm{s}}$, mean scleral radius; NTA, nasal tangent angle at limbus; TTA, temporal tangent angle at limbus; STA, superior tangent angle at limbus; ITA, inferior tangent angle at limbus; T- $\mathrm{NSH}_{12}$ and T-NSH $\mathrm{N}_{13}$, difference between temporal and nasal sagittal heights for chords of 12 and $13 \mathrm{~mm}$, respectively; TSH sagittal height for a $12-\mathrm{mm}$ chord; $\mathrm{MaxSH}_{12}$, maximum sagittal height for a 12 -mm chord. 


\begin{tabular}{|c|c|c|c|c|c|c|}
\hline $\begin{array}{c}\text { Mean (SD) } \\
\text { Median (Range) }\end{array}$ & $\begin{array}{c}\text { Area under } \\
\text { the curve } \\
\text { (AUC) }\end{array}$ & Cut-off point & Sensitivity & Specificity & $\begin{array}{c}95 \% \\
\text { Confidence } \\
\text { Interval }\end{array}$ & P-value \\
\hline ITA $\left(^{\circ}\right)$ & 0.332 & 21.5 & $61.1 \%$ & $34.9 \%$ & $0.204-0.459$ & 0.025 \\
\hline $\mathrm{TSH}_{11}(\mathrm{~mm})$ & 0.643 & 2.07 & $61.1 \%$ & $55.8 \%$ & $0.495-0.791$ & 0.057 \\
\hline $\mathrm{TSH}_{12}(\mathrm{~mm})$ & 0.649 & 2.49 & $61.1 \%$ & $64.0 \%$ & $0.506-0.791$ & 0.048 \\
\hline $\mathrm{TSH}_{13}(\mathrm{~mm})$ & 0.653 & 2.90 & $61.1 \%$ & $62.8 \%$ & $0.509-0.796$ & 0.042 \\
\hline $\mathrm{T}^{-\mathrm{NSH}_{12}(\mathrm{~mm})}$ & 0.646 & 0.025 & $61.1 \%$ & $58.1 \%$ & $0.494-0.799$ & 0.052 \\
\hline T-NSH $13(\mathrm{~mm})$ & 0.657 & 0.085 & $61.1 \%$ & $57.0 \%$ & $0.505-0.809$ & 0.037 \\
\hline $\operatorname{MaxSH}_{12}(\mathrm{~mm})$ & 0.641 & 2.54 & $55.6 \%$ & $69.8 \%$ & $0.490-0.793$ & 0.060 \\
\hline
\end{tabular}

Table 5. Summary of the results of the ROC curve analysis for the detection of keratoconus. Abbreviations: SD, standard deviation; ROC, receiver operating characteristic; ITA, inferior tangent angle at limbus; $\mathrm{TSH}_{11}, \mathrm{TSH}_{12}$, and $\mathrm{TSH}_{13}$, temporal sagittal height for the chords of 11,12 and $13 \mathrm{~mm}$; $\mathrm{T}-\mathrm{NSH}_{12}$ and T-NSH $\mathrm{N}_{13}$, difference between temporal and nasal sagittal heights for the chords of 12 and $13 \mathrm{~mm}$; MaxSH $\mathrm{H}_{12}$, maximum sagittal height for a chord of $12 \mathrm{~mm}$. 